\title{
Discourse Functions of Kama in Arabic Journalistic Discourse from the Perspective of Rhetorical Structure Theory
}

Asem Ayed Al-Khawaldeh*

Department of Modern Languages, Al-alBayt University, Mafraq, Jordan

Corresponding Author: Asem Ayed Al-Khawaldeh, E-mail: asimabujafar@yahoo.com

\section{ARTICLE INFO}

\section{Article history}

Received: November 04, 2017

Accepted: January 13, 2018

Published: May 01, 2018

Volume: 7 Issue: 3

Advance access: March 2018

Conflicts of interest: None

Funding: None

\begin{abstract}
The study aims at examining the functions of the discourse marker Kama in the Arabic journalistic discourse in the light of Rhetorical Structure Theory (RST) proposed by Mann and Thompson (1987). To this end, the study compiled a small-scale corpus of journalistic discourse taken from two prominent Arabic news websites: Aljazeera.net and Alarabia.net. The corpus covers three distinct sub-genres of journalistic discourse: opinion articles, news reports, and sport reports. The journalistic discourse is chosen on the basis that it is considered as the best representative of the contemporary written Arabic and it receives a wide readership in the Arabic-speaking countries. The motivation for the study is that although it is frequently used in the written form of Arabic (particularly in the language of Arabic media), the discourse marker kama is largely neglected and very few has been said about it in the present literature on Arabic discourse markers. The current findings show that kama is found to achieve 290 occurrences in the corpus under investigation. This obviously indicates that kama is commonly used in the language of Arabic journalistic discourse, which calls for paying attention to its usage in such a type of discourse. In the light of Rhetorical Structure Theory (RST) proposed by Mann and Thompson (1987), kama was found to serve four common functions: elaboration (around $50 \%$ ), similarity (around $19 \%$ ), evidence (16\%), and exemplification (13\%). Two functions of kama (similarity and exemplification) are listed in RST while the other two are incorporated.
\end{abstract}

Key words: Kama, Journalistic Discourse, Discourse Marker, Rhetorical Relations, Corpus

\section{INTRODUCTION}

Discourse markers (DMs henceforth) have been the focus of a large number of studies, gaining their importance from the 1970s onwards (Halliday and Hasan 1976, Schiffrin 1987, Blakemore 1987, Fraser 1999, Aijmer 2002). Research on DMs, referred to as "a jungle of publications" (Fisher 2006:2), has attempted to address the main issues of discourse markers, particularly, definition, terminology, functions, classification, and features in different languages from different perspectives and frameworks (Schourup 1999, Schiffrin 2001, Muller 2005, Fraser 2005). Therefore, the literature offers a multiplicity of terms and definitions for DMs. Among the terms are "conjunctions" (Halliday and Hassan 1976), "discourse connectives" (Blakemore 1987(, “discourse operator" (Redeker 1991), "pragmatic marker" (Fraser 1999).

However, though the existence of various competing terms in the literature, the term "discourse markers" has been reported as the most common one of the suggested terms in the literature (Schourup 1999, Aijmer, 2002, Muller 2005). This is because the term "discourse markers" has "a narrower range of reference and has been subject to more precise attempts at definition" (Schourup 1999:230). Moreover, the first comprehensive and influential attempt to study this phenomenon done by Schiffrin (1987), who uses the term DMs and since then it has acquired high popularity and acceptability by a great number of studies following Schiffrin's term (Muller 2005).

As to definitions, if not the most one in the current research on DMs, Schiffrin's definition is one of the most cited and referred to for her book is the first pioneering work on DMs. She (1987:31) defines DMs as "sequentially dependent elements which bracket units of talk" (1987, 31). Another definition proposed by Redeker (1991: 1168) is that DMs as "words or phrases that are uttered with the primary function of bringing to the listener's attention a particular kind of linkage of the upcoming utterance with the immediate discourse context. Another definition is given by Fraser (1999: 950) that DMs are defined as "a class of lexical expressions drawn primarily from the syntactic classes of conjunctions, adverbs, and prepositional phrases. With certain exceptions, they signal a relationship between the interpretations of the segment they introduce, and the prior segment".

Surveying the previous literature on DMs, Schourup (1999) lists and discusses briefly seven popular features 
attributed to DMs, claiming that the first three of them are taken as the most central in the reviewed studies:

1 Connectivity: it refers to the function of connecting two textual segments (clauses sentences, or paragraphs) to each other by indicating the relationship existing between them i.e. a DM links its host segment to the preceding one.

2 Optionality: the notion of optionality, Schourup (1999) points out, can be conceived from two different aspects First, a DM can be omitted from the syntactic structure of its host sentence and this omission has no impact on the grammaticality of the sentence. In other words, the removal of a DM leaves the sentence grammatically intact. Second, a DM has nothing to do with the semantic content of its host sentence; therefore, its removal does not render the sentence meaningless, ambiguous or incomplete.

3 Non-truth conditionality: DMs are generally held that they do not contribute to the truth-condition of their containing sentence. They carry no semantic meaning, which implies that they do not affect the proposition or the truth-conditions of an utterance in which a DM occurs (Schiffrin 1987; Blakemore 1987; Fraser 1999; Erman 2001; Lenk 1998; Wilson 2011).

4 Weak clause association: this feature means that DMs are not part of the syntactic structure of the utterance in which they occur (Schourup 1999; Brinton 1996) or as stated by Sankoff et al. (1997: 195) that DMs do not "enter into construction syntactically with other elements of the sentence". Thus, they display syntactic independence or detachability from their main clause.

5 Initiality: DMs generally tend to occur at the initial position i.e. at the beginning of a sentence or clause, but they may occur in other positions, namely, medial and final.

6 Orality: it is claimed that the use of DMs is a feature of spoken discourse rather than written discourse. However, it is empirically proved that DMs are also common in written discourse.

7 Multi-categoriality: DMs constitute a functional category that is heterogeneous in terms of grammatical word-class. They are drawn from a wide variety of grammatical classes, ranging from adverbs (e.g. however, anyway), conjunctions (e.g. and, or), interjection (e.g. oh, gosh), verbs (e.g. say, listen, and look), to clauses (e.g. you know, you see).

DMs are held to have a wide range of functions according to context in which they are used. Therefore, they are described as "polyfunctional" or "multifunctional" that they have more than one function (Muller 2005). An individual DM often carries a wide range of functions that may sometimes be in an overlapping relation with other DMs' functions (Brinton 1996, Anderson 2001). The number of functions has been claimed to be infinite in context. Being multifunctional is held to be an undisputed property of DMs in the literature (Erman 2001; Aijmer 2002). Therefore, Lenk (1998) and Aijmer (2002) take this feature as a criterion to distinguish DMs from non-DMs due to "the large number of pragmatic values that they can be associated with" (Aijmer
2002: 3). It should be highlighted that multi-functionality of DMs does not trouble speakers or hearers since the intended function can be reached via depending on the context in which they occur (Schiffrin 1987; Fraser 1999; Aijmer 2002; Muller 2005).

However, certain functions are regarded as primary among others according to the approach or frameworks in which they are handled. For example, some studies consider their primary function is to connect discourse units (clauses, sentences, and paragraphs) to each other by indicating the relationships between them in text, thus, contributing to maintain the cohesion and coherence of the text (Halliday and Hasan 1976; Schiffrin 1987; Fraser 1999) while other studies consider that DMs are primarily used to guide the text-receiver by constraining the number of the possible interpretations and minimizing effort and time for him in the mission of understanding the message conveyed by an utterance in context (Blakemore 2002; Andersen 2001; Risselada and Spooren 1998; Aijmer 2002; Muller 2005).

\section{Problem Statement}

Due to the dominance of sentence-grammar, the notion of discourse has not been given a great attention in the Arabic linguistic research. Therefore, the major focus has been limited to a closed set of items known as huruuf al- "atf "con-

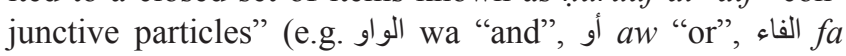
"and, then", ثumma "then", بل bal "but", لكن lakin "but") that connect constituents within sentence limits, paying inadequate attention to their role at the textual level i.e. to connect sentences and paragraphs (Bayshak 1991). However, as a result of the upsurge in western linguistics on discourse and pragmatics, a particular attention has been shifted to the phenomenon of DMs and their role in creating text and signaling relations among discourse units.

This particular focus on Arabic DMs (in spoken or written) as a distinct discourse phenomenon can be attributed to the seminal works of Halliday and Hasan (1976), Schiffrin (1987) and Blakemore (1987). Following these three works, a number of valuable attempts (Al-Batal, 1985; Al-Jubouri 1987; Al-Batal 1990; Sarig 1995; el-Shiyab 1990; Kammensjö 2005; Al-Harahshah and Kanakri 2013; Alazzawie 2014) on examination of the DMs within Arabic context have been carried out by Arab researchers studied at western universities. These attempts, albeit limited, have brought new and crucial insights into the Arabic linguistic research. Thus, a large list of DMs that serve to link text segments above sentence level (to link clauses, sentences, and paragraphs) has been proposed such as كما kama"also", بينما bainamaa "while, whereas", لذلك liðalika "therefore". Most of these studies are concerned with exploring DMs in spoken discourse at the expense of written discourse, resulting in neglecting or giving some DMs little attention. One of these DMs is Kama that has not been adequately dealt with in the surveyed literature on Arabic DMs despite the researcher has observed that kama is widely used in the language of the journalistic discourse, which attracts his attention and inspires him to undertake a study devoted to it. 


\section{Purpose of the Study}

Based on the above discussion, the present study aims to examine and describe the functions of the DM kama and their frequency in the Arabic journalistic discourse from modern perspectives pertaining to the study of DMs, based on corpus-based analysis. Journalistic discourse is considered as the best model and representative of the contemporary written Arabic, well-known as Modern Standard Arabic. The findings are expected to contribute to the linguistic research of Arabic DMs and to enrich Arabic grammar books and teaching material with the common uses of kama in its actual occurrence.

\section{LITERATURE REVIEW}

In the Arabic literature, DMs are defined as "any element in the text which indicates a linking or transitional relationship between clauses, sentences, and paragraphs exclusive of referential or lexical ties" (Al-Batal 1985:2). Saeed and Fareh (2006) argue that Arabic DMs are common cohesive devices that language users employ to mark logical relations between sentences, or any other discourse units joined together by a DM. They argue that DMs can explicitly indicate the function that each sentence has in a text and, therefore, constitute a major linguistic device available for a writer to indicate explicitly the structure of a discourse.

DMs are considered as a pervasive feature of written $\mathrm{Ar}$ abic, where most of the sentences and paragraphs are started with a DM (Ryding 2005). Grammatically, they are heterogeneous i.e. display different grammatical forms such as such as preposition, nouns, phrase, and adverb.

Based on Halliday and Hasan (1976), most of the Arabic literature (Mehamsadji 1988; Al-Shurafa 1994; Bayshak 1991; Hamza 2006) tend to divide DMs into four major

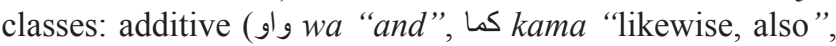
أيضا aidan "too, as well”, علاوة على ذلك "alawat-an 'ala ðalika "moreover"), adversative (لكن ذلاك lakin "but", رغم raghma "though"), causal (بسبب bisabab "because", لأن li?nna "because", طتى hatta "in order to", and temporal (قبل qabla "before", بعد ba 'da "after", عندما 'indama "when").

In the traditional treatment of Arabic that is influenced by sentence grammar, Al-Batal (1985) argues that the textual significance or discourse functions of DMs is "almost non-existent" (3). This traditional treatment, he goes on, does not account for all occurrences of DMs because it is confined to sentence limits. He, therefore, attempts to offer a modern approach to deal with DMs, which combines the study of the semantic, grammatical and discourse features of connectives within their actual textual occurrence.

Lounis (2010) discusses that DMs in Arabic play a communicative role in guiding readers or hearers to understand the interpretation of an utterance intended by a text-producer. He points out that the multifunctionality of DMs is one of the common features of these connecting items, which indicates that one DM can play more than one functional role in discourse. wa "and", he argues, is a good example of this feature that it serves various functions such as swearing, addition, contrast, and sequence.

\section{Kama in the Previous Studies}

As the main focus of the present study, kama is an additive marker, which is originally composed of the preposition s $k a$ "like" and the relative pronoun $\mathrm{r}$ ' $m a$ "which, that" (Al-Hamd and Al-Zoubi 1993; AbdulFattah 2010). In Arabic grammar books, there is a controversy on the function of kama: while some scholars hold that it indicates a similarity between two statements (Badawi et al 2005; Ryding 2005; Cantrino 1975), others think that it indicates لبيلت ta "lil "justification". Astonishingly, grammar books do not provide enough information about the use of kama and they almost use the same examples to demonstrate the case of kama. Moreover, they generally neglect its role in text, particularly, its function in connecting textual units through indicating the relations between them. For the academic theses and papers, they touch on kama in a sketchy manner, referring to its general function of additivity without focusing on its intricate functions in text, particularly, journalistic discourse as the model of MSA. Studies such as Al-Batal 1985; Sarig 1995; Al-Jubouri 1987; and Al-Saif 2012, seem to neglect kama as a DM that contribute to the cohesion and coherence of text. However, only two studies (Lounis 2010, Al-Kohlani 2010) have been found to refer to kama as a DM but briefly and inadequately, describing it on broad terms as indicating additive relation in text.

\section{Theoretical Framework}

The present study employs Rhetorical Structure Theory (RST henceforth) to explore the functions of kama. RST is a text-analytical framework formulated by Mann \& Thompson (1988) to account for the relations that constitute the text structure in language. It is based on the assumption that written discourse is hierarchical and formed of coherence relations that connect textual units to each other. Mann and Thompson (1988) describe their framework as "a linguistically useful method for describing natural texts, characterizing their structure primarily in terms of relations that hold between parts of the text" $(1988,243)$. Its general scope of application is "carefully prepared written monologues" (Mann and Thompson 2000: 1)

RST is used to describe the relations that serve as connections posited between text units (clauses and sentences) to perceive the discourse structure of the whole text. Based on an extensive analysis of more than 400 texts (representing thousands of textual units) of different length (from a single paragraph to several pages) and types (personal letters, letters to editor, administrative memos, political essays, scientific articles and abstracts, travel brochures, advertisements, newspaper articles and editorials), Mann and Thompson (1987-1988) came out with a set of 24 rhetorical relations that represent generally the relations routinely used in natural written text in English (See Table 1).

As a distinct feature of RST, its proposed set of relations are functionally defined, where each relation reflects an affect or function that the writer intends for the reader to understand. When combined consistently, these functional relations contribute to the overall goal of the writer or the text and serve to "make texts effective and comprehensible tools for human communication" (Mann, Matthiessen, and Thompson 1992, 43). 
Table 1. List of rhetorical relations

\begin{tabular}{ll}
\hline Relation name & Relation name \\
\hline Antithesis & Sequence \\
Background & Non-volitional cause \\
Circumstance & Non-volitional result \\
Concession & Otherwise (anti conditional) \\
Condition & Purpose \\
Elaboration & Restatement \\
Enablement & Solutionhood \\
Evaluation & Summary \\
Evidence & Volitional cause \\
Interpretation & Volitional result \\
Justify & Contrast \\
Motivation & Joint \\
\hline
\end{tabular}

Taboada and Mann (2006) outline the most distinctive features of RST as follows:

1-It provides a general descriptive model of relations among text spans whether they are linguistically signaled.

2-It is descriptively used as analytical tool for a wide variety of text types and genres such expository text and news broadcast.

3-It lays foundations for contrastive rhetoric studies.

4-It is a useful model to study narrative discourse and its grammatical and rhetorical properties.

In RST, DMs (termed as cue phrases) contribute to the coherence text through signaling to the reader the relations existing between text units. DMs "guide the text receiver in the recognition of those relations" (Taboada 2006: 568). Moreover, many experimental studies prove that readers process relations with DMs faster than those with no DMs (ibid 2006).

RST distinguishes two types of discourse units, which are related by a rhetorical relation. One of them is called "nucleus", which is the central, necessary and indispensable one for developing a text. The other one is called "satellite", which is less important, secondary. It serves to contribute to the nucleus (e.g. modify, support, or refute). Thus, it can be said that nucleus carries the basic information while satellite carries the additional information. The task of DMs is to mark explicitly the relation that link the nucleus and satellite to each other.

In the light of RST, the present study will examine the functions that kama commonly serves to indicate in the journalist corpus under examination. In other words, we will examine the relations that kama serves functionally to indicate between textual units from the perspective of RST. Since the list of relations proposed in RST is open and flexible, this will enable us to add any potential relation served by kama if and only if it is not listed in RST.

\section{METHODOLOGY}

\section{Data Collection}

As mentioned earlier, the present study intends to find out the functions of kama in the journalistic discourse. The reason for the choice of this genre is that it is one of the most commonly-read types of written discourse as a daily routine for a widespread number of people (Khalil 2000, Al-Kohlani 2012). It is also the best representative of the contemporary written Arabic due to its commitment to Arabic grammatical conventions (Khalil 2000; Abdelfattah 1996; Parkinson, 1991). General speaking, journalistic discourse derives its significance from the fact that it "can provide readers with a certain interpretation and/or conclusion over an event that is reported" (Gill et al 2012).

The data of the corpus has been collected from two prominent news websites, namely, Al-Jazeera and Al-Arabia. These two websites were chosen on the basis that they have the largest readership compared with other Arabic news websites and they are established as international news platform interested in providing a comprehensive coverage of Arab world as well as international affairs. The process of data-collection was conducted over a set period of three moths from 1 March to May 2014, resulting in a corpus of around 200,000 words in number.

\section{Data Analysis}

The analytical framework of the present study is mixed of qualitative as well as quantitative method so as to gain a fuller understanding of the case under investigation. The qualitative aspect, however, constitutes the main thrust of the analytical framework. The first step is to identify and quantify all the occurrences of kama in the current corpus. Then, each occurrence will be described according to the set of relations and their definitions offered in RST discussed above. The focus will be placed on the relations that kama commonly functions to indicate in the corpus.

It should be highlighted that we intend not to force the corpus to suit the pre-existing model in order to allow potential functions other than listed in RST to emerge from the present corpus. Therefore, RST is dealt with here as a stepping stone to come out with an adequate description of the uses of the additive DMs found in the journalistic discourse. More importantly, RST is flexible to include new functions since each text-type has its own peculiarity. Therefore, in the case that a relation found in the corpus has no counterpart in the set of RST, the researcher through the strategy of making "plausibility judgment" will add this new relation to the original set, using the most appropriate term that represent well the new relation detected. What distinguishes the current analysis is that it examines the functions by looking much closer at contexts in which kama is used and let them speak for themselves, which help develop a finer description of the functions in their actual context. Varied functions can be derived when a DM is examined in "particular interpretative contexts" (Schourup 1999: 252).

\section{FINDINGS AND DISCUSSION}

As argued earlier, the study aims at describing the functions of kama in the journalistic discourse. The findings report that the total frequency of kama reached 290 occurrences, which indicates that it is one of the common DMs in the language of journalistic discourse. The study has also found that kama 
served commonly four different functions: similarity, elaboration, exemplification, and evidence. As seen in Table 2, the most frequent functions served by kama in the present corpus are elaboration (around $50 \%$ ), then, similarity (around $19 \%$ ), evidence (around $15 \%$ ), and exemplification (around $13 \%$ ), respectively. The challenge the present study encountered during the analysis was that two of the functions, namely similarity and exemplification, are not listed in RST, therefore, it had to add them to the list.

In this section, each function served by kama will be defined and discussed, accompanied with illustrative examples extracted from the journalistic corpus under consideration. Each example will be followed by its English translation. Kama will be positioned within the English translation in order to help the readers who are unfamiliar with Arabic language understand the given example. Moreover, the symbols $\mathrm{N}$ (refers to Nucleus) and S (refers to satellite) are used within each translation to mark the boundary of the nucleus and the satellite of the relation under examination.

\section{Elaboration Function}

In RST, this relation is defined on broad grounds that "Satellite" (S henceforth) presents additional details about the situation or some element of subject matter which is presented in Nucleus ( $\mathrm{N}$ henceforth) or inferentially accessible in $\mathrm{N}$ in one or more of the ways listed below (Mann and Thompson, 1988: 273). The expected effect of this relation is that "the reader recognizes the situation presented in Satellite as providing additional detail for Nucleus" (ibid).

Based on this definition, it can be stated that elaboration is a cover term which indicates where $\mathrm{S}$ provides $\mathrm{N}$ with additional information or detail through specifying its topic or some of its element (proposition, concept, event, entity, etc.), listing its members or parts, or giving attributes or properties.

Kama is found in the corpus to introduce an elaborative relation between its host segment (satellite) and the preceding one (nucleus). Elaborative kama is detected to occur 146 times in the journalistic corpus under investigation. So it is the most frequent in comparison with other relations served by kama.

In Example (1), the writer is concerned with addressing the rational beyond the Turkish focus on making "air-exclusion" zone along the Turkish-Syrian border. In the nucleus, he argues that it is to provide a staging area for the Syrian opposition as well as the expected transitional government. To elaborate more on the Turkish goals, he supplies the readers with another goal that the buffer zone will provide a safe haven for Syrian refugees. The elaborating satellite introduced

Table 2. Functions of kama

\begin{tabular}{lc}
\hline Function & Frequency (\%) \\
\hline Elaboration & 50.34 \\
Similarity & 19.65 \\
Evidence & 16.20 \\
Exemplification & 13.79 \\
\hline
\end{tabular}

by kama adds more details about these goals and simultaneously provide the reader with a fuller understanding of the benefits of this zone.

$$
\begin{aligned}
& \text { التركيز التركي على المنطقة الآمنة أو العازلة ـالتي تثكل أحد (1) }
\end{aligned}
$$

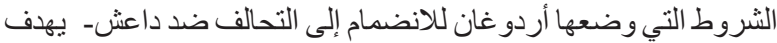

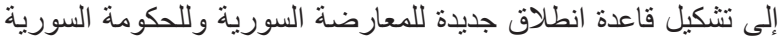

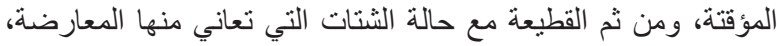

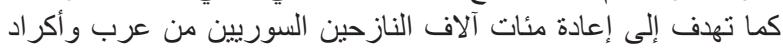

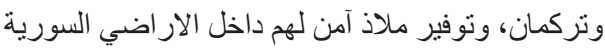

(1) N Turkish focus on establishing a buffer zone - which constitutes one of Turkish President Erdogan's conditions to join the international coalition against ISIS- aims at providing a staging area for the Syrian opposition and the transitional government. S (kama) It also aims at bringing back hundreds of Syrians Arab, Kurdish, and Turkmen refugees and creating a safe haven inside the Syrian territories.

\section{Similarity Function}

Similarity indicates a kind of resemblance, likeness or identicality between two propositions i.e. to indicate that the following segment introduced by a similarity DM (e.g. like, as, similarly) shares some aspects with the preceding one. It should be mentioned that this relation is not listed in RST. Yet, Knott (1998) suggests to add it to the list of relations given in RST under the term comparison relation, comprising similarity and contrast.

Similarity relation seems to be the only function of kama referred to in the literature (Badawi et al 2004, Ryding 2005). According to the present corpus, 57 instances of kama is found to signal to the readers a similarity relation between two textual segments. Astonishingly, the events or states that kama is used to show similarity between them in the corpus are in the past tense form. This may be justified that the journalistic discourse tends mostly to narrate and analyze what has happened rather than what will happen.

In Example (2), kama is used to relate two segments through signaling the similarity holding between them. It is held between two objects: the transitional government which Obama called Russia to support in Syria and the transitional government achieved in Yemen. The segment introduced by kama represents the satellite while the preceding segment represents the nucleus. In fact, the satellite here is secondary information since the main topic given in the nucleus is concerned with establishing a transitional government in Syria not in Yemen.

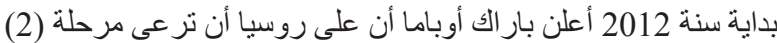

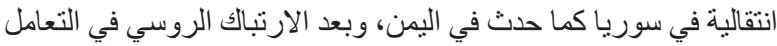

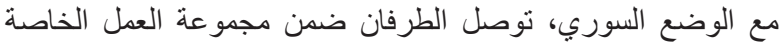

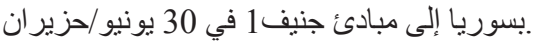

(2) N At the beginning of 2012, Obama announced that Russia must support a transitional stage in Syria $S$ (kama) like what happened in Yemen. After Russian hesitation in dealing with the Syrian situation, both sides reached an agreement on the principle of Geneva held on 30 June. 


\section{Evidence Function}

In RST, evidence relation is simply defined that the nucleus presents a claim that a reader might not believe while the satellite presents some information to make the reader believe the claim or find it credible, thus, the reader's belief in the nucleus is increased (Mann and Thompson 1988:251).

The evidence is deemed as a key device in persuading and influencing the way of thinking or attitude of the reader. It does not intend to clarify or explain but to provide the reader or hearer with what proves the credibility of the topic or proposition at hand. Thus, this increases the assurance of the readers in the writer's argument in text. Lack of giving evidence may lead the reader to doubting what is given by the writer, thereby, a failure in achieving influence on his perspective of attitude. The evidence can be manipulated via different methods such as giving references to figures, names, statistics, studies, facts, experiences, and world knowledge. In Arabic context, providing evidence is seen "crucial to gain the intellectual approval of its propositions" (Zaidan 2006).

According to the results of the current examination, kama is used to introduce evidence relation between two textual segments (nucleus and satellite) achieved 47 occurrences in the present journalistic corpus. The following excerpts will illustrate the function at hand.

In Example (3), the writer offers a statement that there is not any religious text in Islam, justifying violence against peaceful (non-Muslim) people. This statement can be looked at as a claim which needs evidence or proof to support its reliability and authenticity. Therefore, the writer provides in the satellite with a Quranic verse that proves this claim given in the nucleus. For Muslims, the Holy Quran is considered as the most reliable and sacred source relied upon to learn and draw the true teachings of Islam. As pointed in the example, the evidence given in the satellite is introduced by additive DM kama that holds the nucleus and satellite together through signaling to the reader the evidence relation.

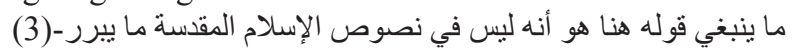

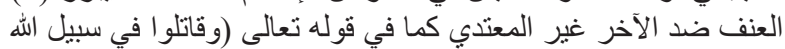

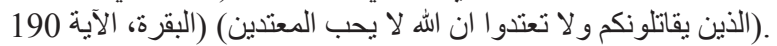

(3) N What should be said here is that there is not any justification in the Islamic sacred texts for violence against peaceful people $S$ (kama) as Allah says in the Holy Quran "Fight in the way of Allah those who fight you but do not transgress. Indeed. Allah does not like transgressors" (Surat Al-Baqarah, 190).

\section{Exemplification Function}

This function is defined that "the consequent proposition represents one instance, type, aspect, or facet of the propositional content of the antecedent. Normally, one representative instance is given which is sufficient to illustrate, clarify, or disambiguate, thus helping to ease processing load" Al-Jubouri (1987:84). The core task of exemplificatory function is to give examples (or examples) on a topic at hand, which is commonly marked with the use of for example, or for instance.

Although the term exemplification is not specified in the list of relations proposed in RST (Mann and Thompson
1988), we use it to cover the occurrences of kama in the current corpus to introduce the exemplificatory relation between textual segments, where the satellite introduced by kama provides an example of a topic or entity stated in the nucleus.

To indicate exemplification relation between the nucleus and satellite is one of the functions served by kama in the journalistic discourse. 40 occurrences of exemplificatory kama are observed in the present corpus. The following examples will illustrate this function

In example (4), the writer argues the intense appearance of the political sectarian in the Arab world after the breaking out of the Arab revolutions and the counter-revolution. This abstract notion is exemplified in the satellite introduced by kama through giving actual instances, namely, Syria, Yemen, Bahrain, and Iraq. This exemplification helps the reader to capture in a more effective way the topic that writer is arguing for in his article.

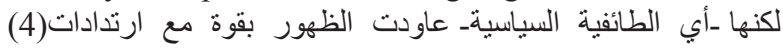

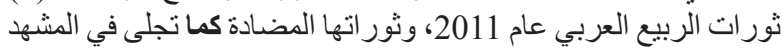

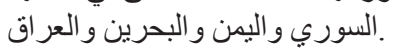

(4) N Political sectarianism has reappeared intensely with the outbreak of the Arab Revolutions 2010 and the subsequent counter-revolution S (kama) as the events manifestly indicate in Syria, Yemen, Bahrain and Iraq.

\section{CONCLUSION}

The goal of the present study was to examine and describe the functions of the discourse marker kama and their frequency in Arabic journalistic discourse from the perspective of Rhetorical Structure Theory (RST) proposed by Mann and Thompson, based on corpus-based analysis. The findings of the present study showed that kama was found to serve commonly four functions in the Arabic journalistic discourse under consideration: elaboration (around $50 \%$ ), similarity (around $19 \%$ ), evidence (around $15 \%$ ), and exemplification (around $13 \%$ ), respectively. Quantitatively speaking, kama occurred 290 times in the corpus, and its most frequent function is elaboration (146 times) while the least frequent one is exemplification (40 times). While elaborative and evidence functions are listed in the set of relations given in RST, similarity and exemplification are incorporated, which can be considered as a contribution to RST as it is flexible to include new functions. In the previous studies, kamā is described generally as an additive discourse marker used to indicate similarity relation between two states or events. However, the present analysis showed that it is multifunctional, serving, besides similarity, other functions.

\section{REFERENCES}

Abdelfattah, Nabil M.S. (1996). Reflections on the sociolinguistic force of journalism in the process of language development in Egypt. In Alaa Elgibali (Ed.), Understanding Arabic: Essays in contemporary Arabic linguistics in honor of el-Said Badawi, ed. Alaa Elgibali, (pp.129136). Cairo: The American University in Cairo.

Abdulfattah, Ashraf. (2010). A corpus-based study of conjunctive explicitation in Arabic. Unpublished Ph.D. thesis, University of Manchester. 
Aijmer K. (2002). English Discourse Particles. Amsterdam: John Benjamins.

Alazzawie, Abdulkhaliq. (2014). The Discourse Marker wa in Standard Arabic. Theory and Practice in Language Studies. 4 (10), 2008-2015.

Al-Batal, Mahmoud. (1985). The cohesive role of connectives in modern expository Arabic text. Unpublished $\mathrm{Ph} . \mathrm{D}$. thesis, University of Michigan.

Al-Batal, Mahmoud. (1990). Connectives as cohesive elements in a modern expository Arabic text. In Mushira Eid, and John McCarthy (Ed.), Perspectives on Arabic Linguistics II, (pp. 234-266). Amsterdam/Philadelphia: John Benjamins.

Al-Jubouri, Adnan. (1987). Computer-aided categorization and quantification of connectives in English and Arabic. Unpublished Ph.D. thesis, University of Aston.

Al-Hamad, Ali and Al-Zoubi, Yusif. (1993). Al muajam al-wafi fi adwat al-nahwi al-arabi. Amman-jordan: Dar Al-amal.

Al-Harahsheh, A., \& Kanakri, M. (2013). The Pragmatic Functions and the Translatability of "Tayib" in Jordanian Spoken Arabic. US-China Foreign Language, 11(3), 196-202.

Al-Kohlani, Fatima. (2010). The function of discourse markers in Arabic newspaper opinion articles. Unpublished Ph.D. thesis, Georgetown University.

Al-Saif, Amal. (2012). Human and Automatic Annotation of Discourse Relations for Arabic. Unpublished Ph.D. thesis, The University of Leeds.

Al-Shiyab, Said. (1990). The structure of argumentation in Arabic: Editorials as a case study. Unpublished Ph.D. thesis, Heriot-Watt University.

Al-Shurafa, Nuha. (1994). Text linguistics and cohesion in written Arabic. Art and humanties, 2 (7), 17-33.

Andersen, Gisle. (2001). Pragmatic markers and sociolinguistic variation: A relevance theoretic approach to the language of adolescents. Amsterdam/Philadelphia: John Benjamin Publishing Company.

Badawi, el-Said, Carter, M. G., and A. Gully. (2004). Modern written Arabic: A comprehensive grammar. London/ New York: Routledge.

Bayshak, Maryam. (1991). A study of cohesion in Arabic. Unpublished Ph.D. thesis, The university of London.

Blakemore, Diane. (2002). Relevance and linguistic meaning: The semantics and pragmatics of discourse markers. Cambridge: Cambridge University Press.

Blakemore, Diane. (1987). Semantic constrains on relevance. Oxford: Blackwell.

Brinton, L. (1996). Pragmatic markers in English. Grammaticalization and discourse functions. Berlin: Mouton.

Erman, Britt 2001. Pragmatic markers revisited with a focus on you know in adult and adolescent talk. Journal of Pragmatics 33: 1337-1359.

Fraser, B. (1999). What are Discourse Markers. Journal of Pragmatics, 31, 931-952.

Fraser, B. (2005).Towards a Theory of Discourse Markers. In Approaches to Discourse Particles edited by K. Fischer. Elsevier Press.
Gill, S. K., Keong, Y. C., Bolte, S., \& Ramiah, S. (2012). Ideological features of vocabulary in news reports of Malaysia's medium of instruction change. GEMA Online TM Journal of Language Studies, 12 (3), 765-787.

Halliday, M. A. K. and R. Hasan. (1976). Cohesion in English. London: Longman.

Hamza, M. (2006). Discourse Markers in Written Arabic. Teachers' College Researchers Journal, 1 (1), 1-252 Retrieved February 26, 2014 from http://www.basiceducation.uomosul.edu.iq.

Kammensjö, Heléne. (2005). Discourse connectives in Arabic lecturing monologue. Göteborg: Acta Universitatis Gothoburgensis.

Khalil, Esam N. (2000). Grounding in English and Arabic news discourse. Amesterdam: John Benjamins Publishing Co.

Knott, Alistair and Robert Dale. (1994). Using linguistic phenomena to motivate a set of coherence relations. Discourse Processes 18: 35-62.

Lenk, Uta. (1998). Marking discourse coherence: Functions of discourse markers in spoken English. Gunter Narr Verlag: Tübingen.

Lounis, Hassane. (2010). Discourse connectives in translation: a relevance-theoretic account with special reference to translation from and into Arabic. Unpublished Ph.D.

Mann, William. C., and Sandra. A. Thompson. (1988) Rhetorical structure theory: Towards a functional theory of text organization. Text 8, 243-281.

Mann, William. C., and Sandra. A. Thompson. (1987). Rhetorical structure theory: a theory of text organization. In Livia Polanyi (ed.). The structure of discourse, NewJersey: Ablex.

Mann, W. C., Matthiessen, C. M. I. M. \& Thompson, S. A. (1992). Rhetorical structure theory and text analysis. In Mann, W. C. \& Thompson, S. A. (Ed.), Discourse description: Diverse linguistic Analyses of a fund-raising text. Amsterdam: John Benjamins, 5, 39-78.

Mann and Thomson. (2000). Toward a theory of reading between the lines: an exploration in discourse structure and implicit communication. Paper presented at $7^{\text {th }} \operatorname{IPrA}$ International Pragmatics Conference.

Mehamsadji, Mokhtar. (1988). Cohesion and text development in written Arabic. Unpublished Ph.D. thesis, University of Salford.

Müller, Simone. (2005). Discourse Markers in Native and Non-native English Discourse. Amsterdam/Philadelphia: John Benjamins Publishing Company.

Parkinson, Dilworth B. (1991). Searching for modern fusha: real-life formal Arabic. Al-Arabiyya 24, 31-64.

Redeker, Gisela. (1991). Linguistic markers of discourse structure. Linguistics 29: 1139-1172.

Risselada, R. \& Spooren, W. (1998). Introduction: Discourse markers and coherence relations. Journal of Pragmatics 30(2), 131-133.

Ryding, Karin C. (2005). A reference grammar of modern standard Arabic. Cambridge: Cambridge University Press. 
Saeed, A. T., \& Fareh, S. (2006). Difficulties encountered by bilingual Arab learners in translating Arabic 'fa' into English. The International Journal of Bilingual Education and Bilingualism, 9(1), 19-31.

Sankoff, Gillian, Thibault, Pierrette, Nagy, Naomi, Blondeau, Hélène, Fonollosa, Marie-Odile,and Gagnon, Lucie. (1997). Variation in the use of discourse markers in a language contact situation. Language Variation and Change, 9:191-217.

Sarig, Lea. (1995). Discourse Markers in contemporary Arabic. Zeitschrift für Arabische Linguistik 30, 7-29.

Schiffrin, D. (1987). Discourse markers. Cambridge: Cambridge University Press.

Schiffrin, Deborah. (2001). Discourse markers: language, meaning and context. In Schiffrin, Deborah, Deborah
Tannen, and Heidi E. Hamilton (ed.). The handbook of discourse analysis. USA: Blackwell publishers.

Schourup, Lawrence (1999). Tutorial overview: Discourse markers. Lingua, 107, 227-265.

Taboada, M. \& Mann, W. C. (2006). Applications of rhetorical structure theory. Discourse Studies. 8 (4), 567-588.

Wilson, Deirdre. (2011). The conceptual-procedural distinction: past, present and future - in V. Escandell-Vidal, M. Leonetti \& A. Ahern (ed.). Procedural Meaning: Problems and Perspectives, pp 3-31. Emerald, Bingley.

Zaidan, suzan. (2006). Representation of viewpoint in opinion discourse. A comparative linguistic investigation of Arabic and British newspapers at time of conflict. Unpublished Ph.D. thesis, The University of Leeds. 